Jurnal Dinamika Bahari

Vol. 8 No. 2 Edisi Mei 2018

\title{
FAKTOR-FAKTOR PENYEBAB RETAKNYA JACKET COOLING DI CYLINDER MAIN ENGINE MT. SEI PAKNING
}

\author{
Suwondo ${ }^{a}$, Edy Warsopurnomo ${ }^{b}$ dan Ahmad Muchlisin ${ }^{c}$ \\ a dan b Dosen Program Studi Teknika PIP Semarang \\ ${ }^{\mathrm{c}}$ Taruna (NIT.50134930.T) Program Studi Teknika PIP Semarang
}

\begin{abstract}
ABSTRAK
Jacket cooling sebagai selimut cylinder liner dan cylinder cover yang didalamnya berupa air pendingin (air tawar) dengan temperatur tertentu yang digunakan untuk menyerap panas yang dihasilkan oleh pembakaran bahan bakar di dalam silinder. Faktor yang mempengaruhi keretakan jacket cooling main engine di bagian cylinder cover sebagai berikut: (a) Pemasangannya (instal), (b) Usia dari material (running hours), (c) Temperatur dan tekanan air pendingin, (d) Perawatan (maintenance), (e) Kualitas air pendingin, (f) Kebocoran pada seal jacket yang sudah diketahui tetapi tidak dilakukan tindakan penanganan (leakage).

Faktor-faktor dari Kekuatan (Strength), Kelemahan (Weakness), Peluang (Opportunities) dan Ancaman (Threats) maka akan dapat dilihat bagaimana solusi untuk mengatasi faktor-faktor yang menyebabkan keretakan pada jacket cooling. Analisis SWOT dapat diterapkan dengan cara menganalisis dan memilah berbagai hal yang mempengaruhi keempat faktornya, kemudian menerapkannya dalam gambar matrik SWOT, dimana aplikasinya adalah bagaimana kekuatan (strength) mampu mengambil keuntungan (advantage) dari peluang (opportunities) yang ada, bagaimana cara mengatasi kelemahan (weaknesses) yang mencegah keuntungan (advantage) dari peluang (opportunities) yang ada, selanjutnya bagaimana kekuatan (strengths) mampu menghadapi ancaman (threats) yang ada, dan terakhir adalah bagaimana cara mengatasi kelemahan (weaknesses) yang mampu membuat ancaman (threats) menjadi nyata atau menciptakan sebuah ancaman baru.

Hasil penelitian diketahui bahwa faktor keretakan terjadi karena kurangnya perawatan serta usia material jacket cooling yang sudah melampaui batas jam kerja dan juga penyetelan temperatur jacket cooling yang tidak stabil. Sebagai mantel pendingin mesin induk jacket cooling sangat berperan dalam menjaga temperatur untuk meningkatkan kinerja dari permesinan tersebut. Keadaan keretakan jacket cooling mengakibatkan pelayaran tertunda.

Peneliti menyimpulkan bahwa keretakan atau pecahnya jacket cooling dapat terjadi karena usia dari material yang sudah melampaui batas jam kerja dan tidak stabilnya temperatur air pendingin. Untuk mengatasi keretakan pada jacket cooling di cylinder cover mesin induk, sebaiknya dilakukan penyetelan temperatur secara bertahap, melakukan pengetesan kadar keasaman air pendingin dan melakukan pengecekan ataupun penggantian terhadap material (jacket cooling) ketika sudah mendekati batas jam kerja yaitu 8000 jam di cylinder cover dan 16000 jam di cylinder liner agar penyebab masalah yang mengakibatkan keretakan jacket cooling di cylinder cover mesin induk teratasi. Melakukan upaya untuk menjadikan temperatur air jacket cooling main engine menjadi lebih normal dapat dilakukan dengan selalu melakukan perawatan pada central cooler, membersihkan plat-plat dari sisi air laut maupun air tawar, melakukan sirkulasi chemical (powder descaler) secara berkala, membersihkan plat-plat di fresh water jacket cooler (FWJC).
\end{abstract}


Suwondo $^{\mathrm{a}}$, Edy Warsopurnomo ${ }^{\mathrm{b}}$ dan Ahmad Muchlisin ${ }^{\mathrm{c}}$

Kata kunci: keretakan, jacket cooling cylinder cover, mesin induk di MT. Sei Pakning.

ABSTRACT

Jacket cooling as a cylinder liner blanket and cylinder cover which is in the form of cooling water (fresh water) with a certain temperature used to absorb heat generated by fuel combustion inside the cylinder. Factors affecting the cracking of the main engine jacket in the cylinder cover as follows: (a) Installation, (b) The age of the material running running, (c) Temperature and pressure of cooling water, (d) Maintenance, (e) Cooling water quality, (f) Leakage on known jacket seals but no leakage measures.

Factors of strength (Strength), Weakness, Opportunities and Threats can then be seen how to solve the factors that cause cracks in jacket cooling. The SWOT analysis can be applied by analyzing and sorting things that affect the four factors, then applying them in SWOT matrix images, where the application is how the strengths are able to take advantage of existing opportunities, how to overcome weaknesses (weaknesses) that prevent the advantages of opportunities, then how strengths are able to deal with existing threats, and the last is how to overcome weaknesses that can make threats become real or create a new threat.

The results revealed that the crack factor occurred due to lack of care and the age of jacket cooling material that has exceeded the working hours and also the unstable jacket cooling temperature setting. As a jacket cooling engine coolant mantle is instrumental in maintaining the temperature to improve the performance of the machinery. The circumstances of the jacket cooling crack resulted in a delayed voyage.

The researchers concluded that cracking or rupture of jacket cooling may occur due to the age of the material that has exceeded the working hour limit and the unstable cooling water temperature. To overcome the crack in the jacket cooling on the cylinder cover of the main engine, it is better to adjust the temperature gradually, to test the acidity of the cooling water and to check or replace the material (jacket cooling) when it is close to the working time limit of 8000 hours on the cylinder cover and 16000 hour in the cylinder liner to cause the problem causing the cracking of jacket cooling on the cylinder cover of the master machine is resolved. Making efforts to make the water jacket cooling temperature of the main engine more normal can be done by always doing maintenance on central cooler, cleaning the plates from the sea or fresh water, doing chemical circulation (powder descaler) regularly, cleaning the plates in fresh water jacket cooler (FWJC).

\section{Keywords: cracking, jacket cooling cylinder cover, main engine in MT. Sei Pakning.}

\section{PENDAHULUAN}

Motor diesel merupakan mesin penggerak utama di MT. Sei Pakning yang berfungsi untuk mengubah tenaga mekanik menjadi tenaga gerak dengan metode penyalaan bahan bakar di dalam mesin itu sendiri. Bahan bakar diinjeksikan di dalam silinder yang berisi udara bertekanan tinggi. Silinder adalah bagian mesin yang sangat penting karena merupakan jantung mesin dan tempat bahan bakar diinjeksikan dan daya ditimbulkan. Bagian dari mesin induk salah satunya adalah cylinder cover yang berfungsi sebagai penutup silinder, cylinder cover ini terdiri dari: (1) distance pipe, (2) stud,fuel valve, (3) stud,exhaust valve, (4) protective cap, (5) nut, oring, bolt, screw, (6) jacket cooling. 
Jacket cooling ini berfungsi untuk menyerap panas yang dihasilkan oleh pembakaran bahan bakar di dalam silinder pesawat yang keluar melalui gas buang. Jacket cooling mempunyai diameter 600 $\mathrm{mm}$ dengan ketebalan $11 \mathrm{~mm}$ yang terbuat dari besi tuang. Dalam pemasangan jacket cooling pada cylinder cover harus sesuai dengan manual book supaya tidak terjadi kesalahan. Jacket cooling harus tahan terhadap panas dan tekanan yang telah ditentukan supaya dapat menyerap panas secara maksimal dan tidak menimbul overheating. Berdasarkan STCW Bab VIII , Nakhoda, Kepala Kamar Mesin (KKM) dan Personil tugas jaga harus menjamin bahwa pelaksaan tugas jaga dilakukan secara aman dan terpelihara. Dalam menjalankan tugas jaga di kamar mesin harus selalu mengecek temperatur, tekanan, serta volume air pendingin. Kelalaian saat tugas jaga dapat menyebabkan retak dan kebocoran jacket cooling no. 2 dikarenakan temperatur air pendingin yang tidak stabil dan kekuatan dari material yang sudah melampaui batas jam kerja.

Perawatan yang dilakukan oleh para masinis kapal dalam menjaga temperatur pendingin mesin induk harus secara baik dan terencana karena merupakan faktor yang sangat penting agar pendinginan mesin induk secara maksimal. Dengan adanya perawatan dan pemeliharaan air pendingin mesin induk secara baik dan terencana, maka kualitas material (jacket cooling) akan terjaga sehingga performa mesin induk akan meningkat. Namun di sisi lain juga para masinis harus rutin melakukan pengecekan terhadap kualitas air pendingin, jam kerja material, serta kestabilan temperatur sehingga jacket cooling akan awet dan terhindar dari keretakan yang menyebabkan kebocoran pada jacket cooling tersebut. Rumusan dalam masalah ini antara lain:

1. Faktor-faktor apa sajakah yang menyebabkan keretakan jacket cooling main engine di MT. Sei Pakning?
2. Apa sajakah dampak keretakan jacket cooling main engine di MT. Sei Pakning?

3. Upaya apa sajakah yang dilakukan supaya tidak terjadi keretakan jacket cooling main engine di MT. Sei Pakning?

Hal ini yang melatarbelakangi peneliti tertarik untuk mengangkat masalah tersebut dan menuangkannya dalam suatu bentuk karya ilmiah berupa penelitian dengan judul: "faktor-faktor penyebab retaknya jacket cooling di cyilinder cover main engine MT. Sei Pakning".

Landasan teori yang mendasari penelitian ini antara lain:

1. Mesin induk

Mesin induk kapal adalah suatu instalasi mesin yang terdiri dari berbagai unit atau sistem pendukung berfungsi untuk menghasilkan daya dorong terhadap kapal, sehingga kapal dapat berjalan maju atau mundur. MT. Sei Pakning tenaga penggerak utama menggunakan mesin diesel 2 tak. Mesin diesel menurut Jusak Johan Handoyo, (2015: 34), dalam buku mesin diesel penggerak utama kapal, menyatakan bahwa mesin diesel adalah suatu pesawat yang mengubah energi potensial panas langsung menjadi energi mekanik, atau juga disebut Combustion Engine Sytem.

Pembakaran (combustion engine) dibagi dua yaitu, (1) mesin pembakaran dalam (internal combustion) adalah pesawat tenaga yang pembakarannya dilaksanakan di dalam pesawat itu sendiri. Contoh: mesin diesel, mesin bensin, turbin gas dan lain-lain. (2) mesin pembakaran luar (external combustion) adalah pesawat tenaga, dimana pembakarannya dilaksanakan di luar pesawat itu sendiri, contoh: turbin uap. Bagian dari mesin induk ini terdiri dari beberapa komponen antara lain, (1) cylinder cover, (2) piston with rod and stuffing box, (3) cylinder liner and cylinder lubrication, (4) crosshead with connecting rod, (5) crank shaft, thrust 
Suwondo $^{\mathrm{a}}$, Edy Warsopurnomo ${ }^{\mathrm{b}}$ dan Ahmad Muchlisin ${ }^{\mathrm{c}}$

bearing and turning gear, (6) mechanical control gear, (7) starting air componen, (8) exhaust valve, (9) fuel oil system, (10) turbocharger system, (11) safety equipment. Sesuai dengan judul yang peneliti ajukan, maka peneliti akan mendetail di bagian cylinder cover dan lebih detailnya ke bagian jacket cooling di cylinder cover main engine.

2. Cylinder cover

Cylinder cover atau cylinder head berfungsi sebagai penutup satu ujung silinder dan tempat lewat udara, bahan bakar diisikan dan gas buang dikeluarkan. Semakin besar ukuran silinder, semakin sukarlah untuk menguasai tegangan-tegangan bahan di dalam pelapis silinder dan juga di dalam tutup silinder.

Dalam pelapis silinder terutama bagian atas (cylinder cover) yang harus mampu menahan suhu-suhu dan tekanan-tekanan tinggi selama terjadinya proses pembakaran. Hal ini dapat dibayangkan betapa banyaknya bahan bakar yang dibakar di ruang bakar. Cylinder cover terdiri dari beberapa bagian antara lain, (1) distance pipe, (2) stud, fuel valve, (3) stud, exhaust valve, (4) protective cap, (5) nut, oring, bolt, screw, (6) jacket cooling

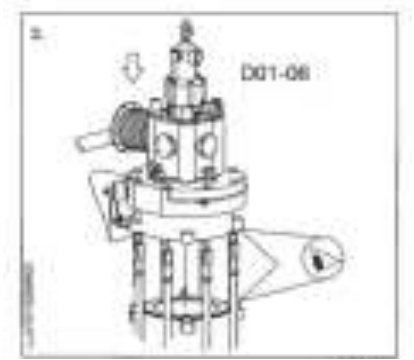

Gambar 1. Cylinder cover mesin induk

\section{Jacket cooling}

Jacket cooling berfungsi sebagai selimut silinder liner yang didalamnya berupa air pendingin (air tawar) dengan temperatur tertentu yang digunakan untuk menyerap panas yang dihasilkan oleh pembakaran bahan bakar di dalam silinder. Spesifikasi Jacket cooling di MT. Sei Pakning adalah sebagai berikut: tipe cooling medium, jenis pendingin air tawar, diameter $600 \mathrm{~mm}$, ketebalan 11 $\mathrm{mm}$, material besi tuang. Secara umum besi tuang (Cast Iron) adalah besi yang mempunyai karbon konten $2.5 \%-4 \%$. Oleh karena itu besi tuang yang kandungan karbon $2.5 \%-4 \%$ akan mempunyai sifat mampu las rendah (sulit dilas).

Karbon dalam besi yang dapat berupa sementit (Fe3C) atau biasa disebut dengan karbon bebas (grafit). Perlu diketahui juga kandungan fosfor dan sulphur dari material ini sangat tinggi dibandingkan baja. Ada beberapa jenis besi tuang (Cast Iron) yaitu: (a) besi tuang putih (white cast iron) besi tuang yang seluruh karbonnya berupa Sementit sehingga mempunyai sifat sangat keras dan getas. Mikrostrukturnya terdiri dari Karbida yang menyebabkan berwarna putih, (b) besi tuang mampu tempa (malleable cast iron) jenis ini dibuat dari besi tuang putih dengan melakukan heat treatment kembali yang tujuannya menguraikan seluruh gumpalan grafit (Fe3C) akan terurai menjadi matriks Ferrite, Pearlite dan Martensite. Mempunyai sifat yang mirip dengan baja, c) besi tuang kelabu (grey cast iron) Jenis besi tuang ini sering dijumpai sekitar $70 \%$ besi tuang berwarna abuabu. Mempunyai grafit yang berbentuk flake. Sifat dari besi tuang ini kekuatan tariknya tidak begitu tinggi dan keuletannya rendah sekali (Nil Ductility).

Material dari jaket pendingin di MT. Sei Pakning termasuk jenis besi tuang kelabu. Menempel pada bagian cylinder liner dan yang bagian atas menempel pada cylinder cover, air pendingin dipasok dari bagian bawah jaket pendingin. Pada cylinder liner, air langsung menuju ke bagian atas jaket pendingin. Sedangkan pada cylinder head air melewati lubang pendingin dari atas jaket pendingin, air mengalir melalui sambungan air ke jaket 
pendingin di bagian bawah penutup silinder.

Cylinder dan exhaust valve didinginkan oleh air tawar, air tawar mengalir melalui pipa utama sepanjang mesin induk dan melalui cabang ke jaket pendingin masing-masing silinder. Air dialirkan dari jaket pendingin sampai penutup silinder kemudian kembali ke manifol untuk disirkulasikan ke pendingin air segar (central cooler).

Mantel air pendingin ini harus memanjang sesuai langkah toraknya, sehingga ekspansi yang tidak seimbang dari material dapat dicegah dan juga supaya film minyak pelumas tidak rusak akibat suhu yang terlalu tinggi (overheating). Pada umumnya bagianbagian motor yang terkena suhu yang luar biasa, mendapat pendinginan lebih.

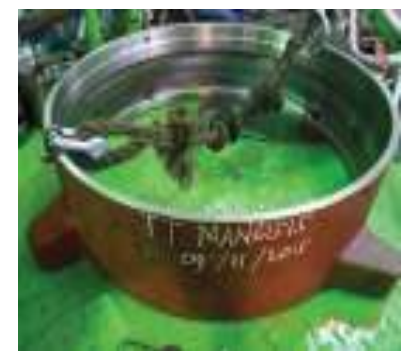

Gambar 2. Jacket cooling bagian cylinder cover

Pendingin adalah suatu media yang berfungsi untuk menyerap panas. Panas tersebut didapat dari hasil pembakaran bahan bakar di dalam cylinder. Di dalam sistem pendingin terdapat beberapa komponen yang bekerja secara berhubungan antara lain : cooler, pompa sirkulasi air tawar, pompa air laut, strainer pada air laut dan sea chest. Dari keempat komponen inilah yang sering menyebabkan kurang maksimalnya hasil pendinginan terhadap Motor Induk. Air pendingin dalam fungsinya sangat vital dalam menjaga kelancaran pengoperasian motor induk. (P.Van Maanen, 2002, Motor Diesel Kapal, hal 8.1, Noutech).
4. Prinsip kerja pendinginan mesin induk

Sistem pendinginan ini bertujuan untuk mencegah terjadinya kelelahan bahan, karena pemanasan berlebihan yang dapat mengakibatkan turunnya kinerja pada mesin itu. Tidak adanya perawatan terhadap air pendingin mesin induk dan pesawat bantu lainnya dapat berakibat fatal dan serius. Jenis sistem pendinginan antara lain:

a. Sistem pendinginan tertutup

Sistem pendingin tertutup adalah sebuah sistem dengan media pendinginnya menggunakan air tawar yang digunakan secara terus-menerus bersirkulasi untuk mendinginkan Motor/Mesin tersebut. Jadi sebelum dimasukan kembali ke dalam Motor/Mesin, air tawar pendingin tersebut dimasukkan ke dalam alat pemindah panas yang disebut fresh water cooler untuk menurunkan media air tawar tersebut pada suhu antara $50^{\circ} \mathrm{C}-60^{\circ} \mathrm{C}$. Sedangkan alat pemindah panas yang dipergunakan untuk menyerapnya panas air tawar adalah media air laut yang setelah mendinginkan air tawar langsung dibuang ke laut.

b. Sistem pendinginan terbuka

Sistem pendinginan terbuka adalah sistem media air laut sebagai media pendinginnya setelah melakukan fungsi pendinginan, selanjutnya air laut tersebut langsung dibuang ke luar, umumnya media pendingin yang dipakai adalah air laut, sistem media terbuka ini mempunyi dampak negatif terhadap material yang bersentuhan langsung dengan air laut, akan mudah berkarat, kotor, penyempitan saluran pipa-pipa pendingin dan lainnya. 
Suwondo $^{\mathrm{a}}$, Edy Warsopurnomo ${ }^{\mathrm{b}}$ dan Ahmad Muchlisin ${ }^{\mathrm{c}}$

5. Kerangka pikir penelitian

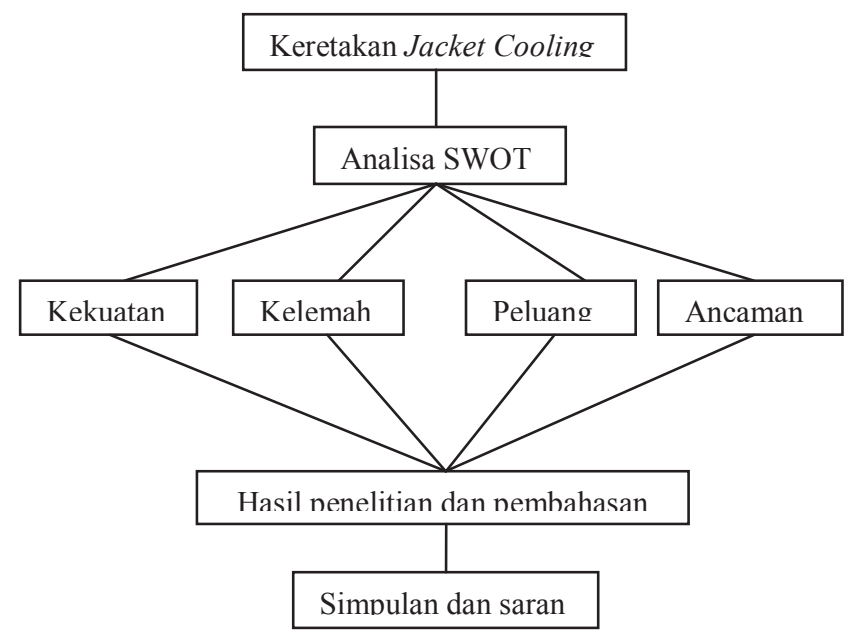

Gambar 3. Kerangka Pikir Penelitian

\section{METODOLOGI PENELITIAN}

Metodologi penelitian adalah suatu usaha untuk menemukan, mengembangkan dan menguji kebenaran ilmiah. Metode penelitian ini digunakan untuk memperoleh gambaran suatu metode dengan harapan memberikan arah penelitian dan tujuan yang telah ditetapkan.

\section{A. Gambaran Umum Objek Yang Diteliti}

Peneliti pada bab ini akan menjelaskan gambaran umum terhadap materi atau objek yang akan diteliti menggunakan metode SWOT. Dalam melaksanakan penelitian ini, peneliti mengumpulkan data-data dari mesin induk di MT. Sei Pakning. Adapun spesifikasi tersebut seperti di bawah ini:

$\begin{array}{ll}\text { Nama } & : \text { Mesin induk } \\ \text { Type } & : \text { Hyundai-ManB\&W } \\ \text { 6S42MC7 } & : \text { Hyundai Heavy } \\ \text { Maker } & \\ \text { Industries Co.Ltd } & \\ \text { Max H.P/KW/RPM } & : 8820 \mathrm{BHP} / 6480 \mathrm{KW} / \\ \text { 136 RPM } & \\ \text { Cyl. Number } & : 6 \text { cylinder } \\ \text { Diameter silinder } & : 420 \mathrm{~mm} \\ \text { Langkah piston } & : 1.764 \mathrm{~mm}\end{array}$

\section{B. Analisa Hasil Penelitian}

Analisa merupakan langkah awal untuk mencari penyelesaian suatu masalah. Didalamnya berisikan penyebab timbulnya masalah sekaligus untuk mencari penanggulangan dari masalah tersebut. Dari hasil wawancara kepada Masinis 1 dan KKM, dapat disimpulkan bahwa faktor yang menyebabkan retaknya jacket cooling di cylinder cover yaitu:

\section{Pemasangannya (install)}

Pemasangan jacket cooling di cylinder cover harus sesuai dengan instruksi dan aturan-aturan yang ada di manual book untuk mendapatkan hasil pemasangan yang optimal. Maka dari itu dalam pemasangan harus memperhatikan hal-hal sebagai berikut antara lain:
a. Hydrolick pressure, mounting : 900 bar
b. Exhaust valve stud, screwing in torque : $200 \mathrm{Nm}$
c. Cylinder cover stud, check distance $: 110 / 3 \mathrm{~mm}$

2. Usia dari material

Material dari jacket cooling ini terbuat dari besi tuang kelabu, jacket cooling tersebut menempel pada bagian cylinder liner dan cylinder head masing-masing mempunyai batas usia pakai yang telah dianjurkan dari pabriknya (Maker). Pada cylinder liner batas maksimum yang dianjurkan yaitu 16000 jam sedangkan pada cylinder head batas maksimumnya 8000 jam. Maka dari itu perlu diadakan pembaruan jika sudah mencapai batas maksimum.

3. Temperatur dan tekanan air pendingin

Temperatur air pendingin yang masuk dalam jacket cooling harus dijaga agar tetap stabil dalam pendinginan mesin dan mesin tetap dalam kondisi yang prima. Dalam menjaga kestabilan temperatur mesin induk (jacket cooling) harus mengacu 
pada manual book instruction antara lain:

a. Temperatur masuk ke mesin induk : $65-70^{\circ} \mathrm{C}$

b. Temperatur keluar dari masingmasing cylinder : $75-80^{\circ} \mathrm{C}$

c. Temperatur keluar dari mesin induk ke FWG : $80^{\circ} \mathrm{C}-85^{\circ} \mathrm{C}$

d. Tekanan air pendingin : $3.5-4.5$ bar

Jika dalam menjaga kestabilan temperatur dan tekanan air pendingin tidak diperhatikan secara cermat, maka hal tersebut akan mempengaruhi dari kualitas jacket cooling tersebut.

4. Perawatan (maintenance)

Kualitas air pendingin, kebocoran pada seal jacket yang sudah diketahui tetapi tidak dilakukan tindakan penanganan (leakage). Untuk menunjang kelancaran dalam menjaga temperatur dari mesin induk di kapal maka jacket cooling perlu adanya perawatan, perawatan yang dilakukan di jacket cooling cylinder cover main engine antara lain, (1) Menjaga seluruh ruangan pendingin di dalam kepala silinder tetap bersih dari kotoran atau benda asing yang tertinggal didalamnya serta pastikan terisi penuh dengan air pendingin, jangan sampai terjadi adanya udara terjebak didalamnya karena dapat menyebabkan panas yang tidak merata, (2) Menjaga suhu air pendingin tetap stabil pada saat mesin penggerak utama bekerja ataupun sedang tidak bekerja. Perawatan rutin yang dilakukan yaitu pengecekan pada pipa-pipa, lubang pendingin dan bagian atas antara silinder dan cylinder head dan bagian bawah exhaust valve. Perawatan rutin lainnya antara lain:

a. Pencegahan korosi

Berbagai jenis pencegahan yang ada namun, umumnya hanya bernitrat-borat yang dianjurkan. Pengolahan air pendingin menggunakan minyak penghambat tidak direkomendasikan, karena perlakuan tersebut melibatkan risiko deposit tak terkendali yang dapat merusak lingkungan. Undang-undang untuk pembuangan air limbah, termasuk air pendingin, melarang menggunakan kromat untuk menghilangkan kotoran air pendingin yang menjadi penghambat dan kromat tidak boleh digunakan pada air pendingin yang terhubung dengan fresh water generator (FWG) air tawar.

b. Kualitas air pendingin

Air pendingin jacket cooling lebih baik menggunakan air tawar yang dari hasil proses kondensasi (freh water generator). Pengecekan yang dilakukan antara lain:

1) Hardness $\max 10^{0} \mathrm{dH}(10$ ppm $\mathrm{CaO})$

2) $\mathrm{pH} 65-80$ (at $20^{\circ} \mathrm{C}$ )

3) Chloride $50 \mathrm{ppm} \quad(50$ $\mathrm{mg} /$ liter)

4) Sulphate $50 \mathrm{ppm} \quad(50$ $\mathrm{mg} /$ liter)

5) Silicate 25 ppm (25 $\mathrm{mg} / \mathrm{liter}$ )

c. Pengecekan dan pembersihan

Lakukan pengecekan pada pipa-pipa, lubang pendingin dan bagian atas antara cylinder liner dan cylinder head dan bagian bawah exhaust valve.

1) Pengecekan mingguan, yaitu: Pengambilan sampel air tawar pada saat mesin beroperasi. Pengecekan kondisi air pendingin, pengetesan nilai $\mathrm{pH}$ dan konten chloride.

2) Tiga bulanan

Pengambilan sampel air pendingin dan kemudian dilakukan analisis laboratorium (inhibitor, sulphate, iron, total salinity) 
Suwondo $^{\mathrm{a}}$, Edy Warsopurnomo ${ }^{\mathrm{b}}$ dan Ahmad Muchlisin ${ }^{\mathrm{c}}$

5. Tahunan

Lakukan pengosongan untuk flushing jacket cooling dengan air tawar hingga bersih dan lakukan pengisian kembali.

Kemudian masukkan analisa SWOT, yaitu untuk mencari nilai faktor tertinggi, faktor internal ancaman dari dalam kapal mengenai kekuatan (strengths) dan kelemahan (weaknesses) serta faktor-faktor eksternal yaitu ancaman dari luar kapal mengenai peluang (opportunities) dan ancaman (threats). Hasil penelitian faktorfaktor internal dan eksternal adalah sebagai berikut:

Tabel 1. Faktor Internal Eksternal

\begin{tabular}{|c|c|c|c|}
\hline \multicolumn{4}{|c|}{ FAKTOR INTERNAL } \\
\hline & KEKUATAN (S) & & KELEMAHAN (W) \\
\hline 1 & ABK yang terampil dan professional & 1 & Pemberdayaan ABK yang belum maksimal \\
\hline 2 & Kualitas material yang bagus & 2 & Perawatan yang belum maksimal \\
\hline 3 & Material yang kuat dan tahan terhadap getaran & 3 & Kurang lengkapnya sarana spesial tooks \\
\hline 4 & Sistem kontrol yang mash aktif & 4 & Tidak stabilinya temperatur air pendingin jacket \\
\hline \multicolumn{4}{|c|}{ FAKTOR EKSTERNAL } \\
\hline & PELUANG (0) & & $\operatorname{ANCAMAN}(\mathbf{T})$ \\
\hline 1 & Reputasi perusahaan yang bagus & 1 & Meningkattya gaji ABK \\
\hline 2 & Penanganan perawatan yang optimal & 2 & Terhambatnya pengoperasian kapal \\
\hline 3 & Kapal bisa di charter oleh perusahaan lain & 3 & Perrsahaan tidak akan lulus audit \\
\hline 4 & Penssahaan akan meningkatkan kualtas suku cadang & 4 & Meningkatnya biaya operasional kapal \\
\hline
\end{tabular}

Berdasarkan identifikasi faktorfaktor internal dan eksternal sebagaimana terlihat dalam tabel di atas, pada tahap selanjutnya dilakukan penilaian terhadap faktorfaktor tersebut. Penilaian dilakukan melalui penentuan Nilai Urgensi (NU), Bobot Faktor (BF), Nilai Bobot Dukungan (NBD), Nilai Bobot Keterkaitan (NBK) dan Total Nilai Bobot (TNB), dengan rumus sebagai berikut:

$$
\mathrm{BF}=\frac{\mathrm{NU}}{\sum \mathrm{NU}} \times 100 \%, \quad \mathrm{NBD}(\mathrm{S} 1)=\frac{\mathrm{BF}(\mathrm{S} 1) \times \mathrm{ND}(\mathrm{S1})}{100}
$$$$
\operatorname{NBK}(S 1)=\frac{B F(S 1) \times N R K(S 1)}{100}, \operatorname{TNB}\left(S_{1}\right)=\operatorname{NBD}\left(S_{1}\right)+B K\left(S_{1}\right)
$$

Tabel 2. Hasil penghitungan BF, NBD, NBK dan TNB

\begin{tabular}{|c|c|c|c|c|c|c|c|c|c|c|}
\hline No. & EAKTORIXIERNAL HSTERNAL. & Ein & $\mathrm{N}$ & ( & NiW & NBS & INB & FK & ML & TSB \\
\hline \multicolumn{11}{|c|}{ BUEOQR LIIRKAL } \\
\hline 1 & 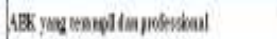 & $17, \mathrm{M}$ & 3 & QS4 & 100 & MIY) & 071 & & & \\
\hline ; & 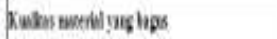 & $17, \mathrm{M}$ & 3 & as & 340 & 0017)85 & Lit & 1 & & \\
\hline j & Montes & $H y$ & 3 & Q18 & 160 & 06571085 & 10 & i & & \\
\hline 4 & 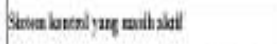 & 6,7 & : & tat & 448 & 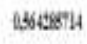 & 4.8 & & s) & 23) \\
\hline$\dot{4}$ & 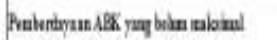 & 9,4, & 4 & 49 & 6.20 & 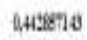 & Q4 & & & \\
\hline 6 & Punvisa ray bias alomal & 4,2 & 4 & $6.5 \%$ & $60 \%$ & 0,9400s: & LS & 1 & & \\
\hline$?$ & 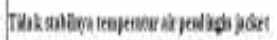 & 10,7 & 1 & $0 \mathrm{x}$ & $M T^{\circ}$ & QTLETH & 104 & : & & \\
\hline 8 & Xeng hrplappa una pirabir ood & $9,4 \mathrm{H}$ & 1 & 4t1 & 4 & 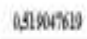 & ats & & $\mathbb{N}$ & 246 \\
\hline \multicolumn{11}{|c|}{ FAITORERSTIEYLL } \\
\hline 9 & 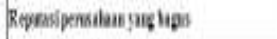 & 14.9 & 3 & at & 780 & 111 เมีแ & 154 & & & \\
\hline 10 & 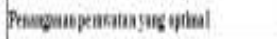 & 0.7 & 3 & an & M? & 098 & 13 & i & & \\
\hline II & 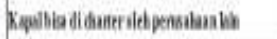 & 35 & $i$ & ant & M? & AMEGS & $a y$ & & & \\
\hline it & 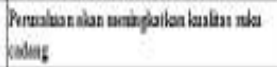 & 4.2 & 1 & uis & 11,40 & 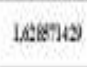 & 206 & 1 & 0 & 3,33 \\
\hline is & Metuplarma piatir: & 10,7 & $t$ & ett & 11,93 & 1,24:4 & 1,46 & & & \\
\hline If & 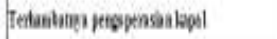 & 17,9 & 1 & 271 & 820 & 1,156864 & 218 & $i$ & & \\
\hline If & 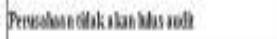 & 10.7 & 3 & as & 813 & Astogen & W19 & & & \\
\hline 16 & 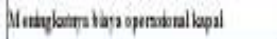 & 1980 & i & แๆ & 8.80 & 139usis! & 24 & 1 & t & 46 \\
\hline
\end{tabular}

Berdasarkan perhitungan SWOT di atas kemudian didapatkan matrik strategis sebagai berikut:

\section{Tabel. 3 Matrik strategi}

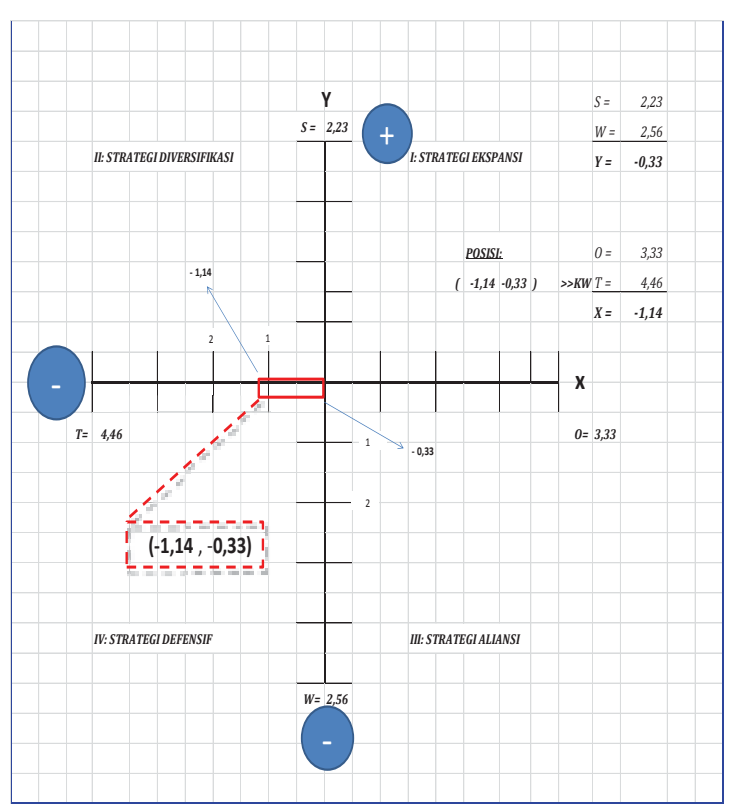


Pada tabel di atas dapat dilihat hasil matrik bahwa posisi koordinat menunjukkan pada posisi $(-0,14$, $0,33)$ yang menunjukkan bahwa strategi yang digunakan adalah strategi defensif yaitu strategi Weakness dan Threats (strategi WT) dimana strategi WT merupakan strategi dengan situasi yang tidak menguntungkan, sehingga perusahaan harus menghadapi berbagai ancaman dari luar dan kelemahan dari dalam.

\section{PEMBAHASAN MASALAH}

1. Faktor-faktor yang mempengaruhi retaknya jacket cooling di cylinder cover main engine antara lain:

a. Perawatan yang belum maksimal

Perawatan yang belum maksimal meliputi pengecekan kualitas air pendingin mesin induk yang sangat penting untuk menjaga tingkat keasamannya, karena dari jeleknya kualitas air pendingin akan timbul kotoran yang menempel pada dinding ruang pendingin, sehingga proses pendinginan mesin induk tidak merata (maksimal). Jeleknya kondisi air pendingin juga bisa mengikis material khususnya jacket cooling sehingga material mudah rapuh dan mudah pecah jika terjadi perubahan temperatur yang secara drastis.

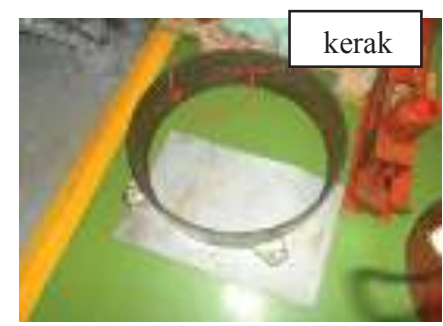

Gambar 4. Jacket cooling terdapat kerak

Sedangkan di MT. Sei Pakning pengetesan terhadap air pendingin mesin induk maupun generator jarang dilakukan oleh para Masinis, biasanya para Masinis melakukan pengecekan dan pengetesan sebulan sekali, ada yang tiga bulanan bahkan hanya sekali dalam masa kontrak kerjanya. Hal tersebut sangat disayangkan karna air (jacket cooling) mengandung adanya mineral-mineral yang terlarut di dalam air selain menimbulkan endapan padat, air juga dapat memicu terjadinya korosi galvanik. Jadi semakin jarang melakukan pengecekan dan pengetesan terhadap kualitas air pendingin akan lebih besar peluang untuk menciptakan korosi pada material jacket cooling yang terbuat dari besi tuang.

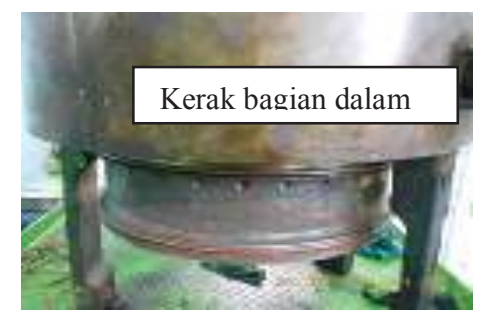

Gambar 5. Bagian dalam terdapat kerak

b. Temperatur air pendingin jacket tidak stabil

Temperatur dan tekanan air pendingin jacket cooling main engine sesuai dengan standar di buku panduan yaitu:

Jacket cooling water inlet (JCW) : $65^{\circ} \mathrm{C}-70^{\circ} \mathrm{C}$

Temperatur keluaran JCW

$75^{\circ} \mathrm{C}-80^{\circ} \mathrm{C}$

Tekanan JCW

3.5 - 4.5 bar

Sedangkan temperatur saat kapal berolah gerak sangat tidak stabil karna mesin induk kadang on running secara tiba-tiba stop engine. Perubahan laju mesin secara tiba-tiba menyebabkan temperatur air pendingin ketika disetel (dibuka) untuk meningkatkan temperatur, katup belum pada posisi maksimal harus diputar kembali (ditutup) untuk segera diturunkan ketika mesin kondisi stop engine. Hal tersebut akan mempengaruhi kekuatan dari material (jacket cooling) karena 
Suwondo $^{\mathrm{a}}$, Edy Warsopurnomo ${ }^{\mathrm{b}}$ dan Ahmad Muchlisin ${ }^{\mathrm{c}}$

suatu benda akan mengalami kelelahan (fatique) jika terjadi perubahan temperatur dari panas ke temperatur dingin secara cepat. Serta sangat dibutuhkan penyetelan temperatur air jacket cooling pada katup keluaran ke mesin induk secara hati-hati dan berkala untuk menghindari naik turunnya temperatur secara drastis.

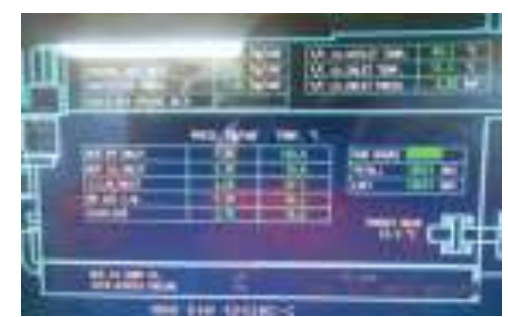

Gambar 6. Temperatur Jacket cooling

Jacket cooling water (JCW) inlet $: 67.30^{\circ} \mathrm{C}$ JCW outlet pada cylinder no. $2: 73^{\circ} \mathrm{C}$ Tekanan JCW

: 3.09 bar

Dilihat pada kontrol panel di atas temperatur masih belum stabil. Pada saat kapal berolah gerak pompa preheater masih beroperasi untuk membantu meningkatkan temperatur air jacket cooling, kemudian pada saat membuka valve outlet di pompa air pendingin yang menuju ke mesin induk, maka dengan cepat temperatur naik hingga melebihi temperatur yang kita harapkan. Kemudian dengan cepat pula menutup kembali valve oulet tersebut, dan temperatur secara otomatis akan turun dengan cepat. Pada faktor inilah yang sangat dominan dalam penyebab keretakan jacket cooling main engine mengapa demikian karena perpindahan suhu panas ke suhu dingin secara drastis dan berkesinambungan selama berolah gerak sangat berpengaruh terhadap kekuatan material jacket cooling tersebut.

2. Dampak dari keretakan jacket cooling cylinder cover
a. Terhambatnya pengoperasian kapal

1) Dikarenakan air pendingin di tangki ekspansi habis

Air pendingin di tangki ekspansi antara low temperature (LT) dan high temperture (HT) menjadi satu tangki yang hanya dipisah dengan sekat yang tengahnya berlubang. Air pendingin LT dan HT tetap menjadi satu tangki dengan katup keluaran HT yang menuju ke mesin induk dan katup keluaran LT yang menuju ke generator. Katup pengisian pada tangki ekspansi termasuk katup otomatis dengan sistem kontrol berkelanjutan (continuous control) dengan jenis proporsional kontrol yaitu untuk mengontrol suatu proses seiring dengan berubahnya suatu kondisi. katupnya mampu bergerak secara terus-menerus (continue) untuk mengubah derajat pembukaan atau penutupan. Pada hal ini air pendingin sebagai media yang dikontrol dan pelampung sebagai media pengontrol (sensor) untuk level air pendingin.

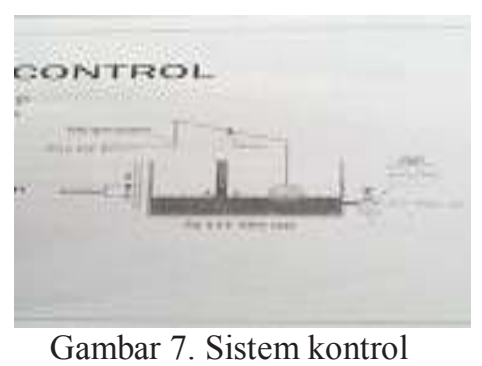

Namun pada kenyataan pada sistem kontrol di tangki ekspansi MT. Sei Pakning yang digunakan untuk mengetahui level air dan sebagai sensor untuk membuka atau menutup katup pengisian (fill up valve) sudah tidak berfungsi (rusak). Di samping itu katup masuk pengisian air pendingin LT patah di bagian handle valve tetapi belum ada tindakan perbaikan atau penggantian katup 
tersebut dikarenakan katup pengisian pada air pendingin HT masih berfungsi dengan baik dan tangki LT dengan HT menjadi satu hanya dipisahkan dengan sekat dengan tengahnya berlobang. Jadi pada saat melakukan pengisian di tangki HT secara otomatis tangki LT juga ikut terisi. Sehingga para oiler/Masinis jaga dalam melakukan pengisian air pendingin dilakukan dengan membuka katup pengisian air pendingain HT secara manual dan selalu mengecek kondisi level dari air pendingin tersebut.

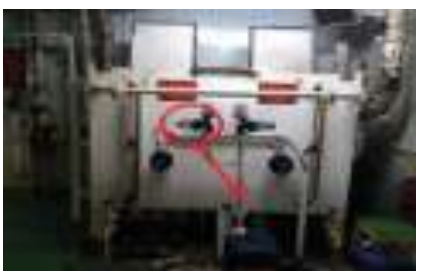

Gambar 8. Valve ekspantion tank rusak

Pada saat terjadinya kebocoran pada seal ring antara permukaan liner dengan cylinder cover ditandai dengan adanya rembesan dari celah-celah seal ring tersebut dan dibiarkan tanpa ada tindakan. Kemudian pada saat kejadian retaknya jacket cooling bagian bawah pada cylinder cover dengan tekanan air pendingin 3.09 $\mathrm{kg} / \mathrm{cm}^{2}$ air secara cepat mengalir keluar dan memenuhi area mesin induk. Dalam penanganan tersebut katup keluaran tangki ekspansi yang menuju mesin induk dan katup keluaran di silinder no. 2 yang terjadi keretakan tidak segera ditutup. Oleh sebab itu juga air di tangki ekspansi cepat habis karena tidak segera dilakukan pengisian secara manual.

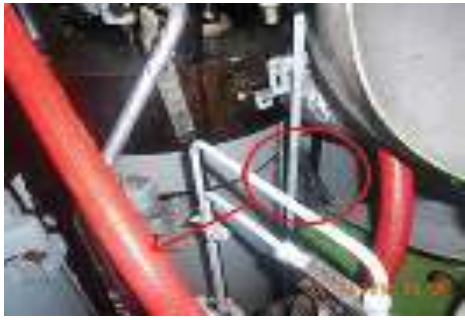

Gambar 9. Air pendingin keluar

2) Terjadinya Blackout

Blackout terjadi karena air pendingin di tangki ekspansi low temperature (LT) dan high temperature (HT) habis. Aliran air pendingin LT ke generator yang digunakan untuk mendinginkan generator berkurang sehingga mengalami overheating dan otomatis sistem kontrol yang ada di generator dengan batas tekanan tertinggi yang telah diatur sebelumnya akan bekerja untuk menshutdown generator tersebut.

3) Main bearing generator no. 2 cylinder no. 1 ngejump

Terjadinya main bearing ngejump dikarenakan tidak ada aliran pendinginan yang menuju ke generator tepatnya pada bagian piston, sehingga crank pin bearing yang menempel pada main bearing lengket dengan crank shaft dan terbakar. Seperti gambar berikut:

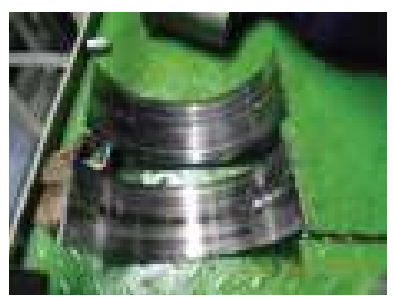

Gambar 10. Main bearing terbakar

b. Meningkatnya biaya operasional kapal

Dengan adanya kerusakan pada mesin induk dan permesinan lainnya akibat dari keretakan tersebut, kemungkinan besar perusahaan akan mengeluarkan biaya lebih untuk 
Suwondo ${ }^{\mathrm{a}}$, Edy Warsopurnomo ${ }^{\mathrm{b}}$ dan Ahmad Muchlisin ${ }^{\mathrm{c}}$

melakukan perbaikan terhadap jacket cooling dan terhadap kerusakan di generator tersebut. Perusahaan akan menyediakan suku cadang dengan jumlah yang lebih dan kualitas lebih bagus daripada suku cadang sebelumnya.

3. Upaya yang dilakukan untuk pencegahan keretakan pada jacket cooling

Pada saat kapal dalam keadaan berlayar mengalami trouble engine yaitu terjadinya kebocoran air pendingin akibat retaknya jaket cooling di cylinder cover main engine. Langkah pertama yang harus dilakukan bagi Masinis jaga dengan menurunkan rpm mesin induk kemudian menuju ke mesin induk dan lakukan penutupan pada katup keluaran yang mengalami kebocoran (silinder no. 2). Apabila tidak dapat dilakukan maka lakukan penutupan pada katup masuk air pendingin di mesin induk dan apabila juga tidak dapat dilakukan karena panasnya air jacket cooling yang keluar dan sangat berbahaya bagi keselamatan diri, lakukan penutupan pada katup keluaran menuju mesin induk di tangki ekspansi.

Setelah katup keluaran di silinder no. 2 ditutup, lakukan pemberhentian mesin induk (stop engine). Kemudian biarkan pompa jacket cooling beroperasi untuk mensirkulasikan air pendingin di silinder lainnya agar tidak terjadi panas berlebihan di masing-masing silinder. Lakukan pengamatan terhadap keretakan tersebut seperti gambar:

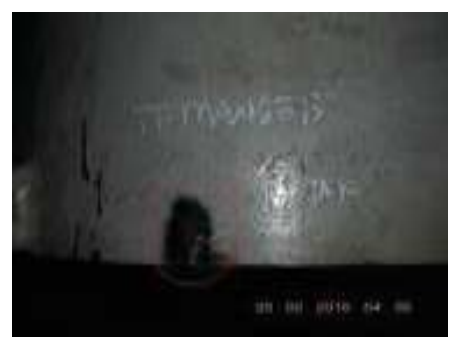

Gambar 11. Keretakan pada jacket cooling
Keretakan cukup parah (lebar) dan posisinya berada pada bagian bawah yang langsung mendapati celah sambungan ke cylinder liner. Dari parahnya keretakan tersebut KKM mengambil keputusan untuk mengganti dengan yang baru yang kebetulan suku cadang pengganti masih ada. Kemudian KKM menginstruksikan ke Masinis 1 untuk melakukan top overhoul penggantian jacket cooling pada saat itu juga setelah kondisi mesin agak dingin. Seperti gambar berikut:

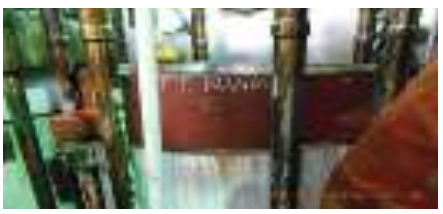

Gambar 12. Penggantian jacket cooling baru

Proses penggantian memerlukan waktu \pm 10 jam dari jam 02.00 LT hingga \pm 12.00 LT dan siap melakukan engine test. Setelah mesin induk dinyatakan aman dan siap beroperasi, kapal melanjutkan pelayaran menuju terminal muat di Cilacap.

Langkah-langkah yang harus dilakukan untuk mencegah terjadinya keretakan pada jacket cooling antara lain:

a. Menjaga kualitas air pendingin

Air pendingin sangat berperan penting dalam mempertahankan performa mesin induk. Maka dari itu kualitas dari air pendingin harus diperhatikan untuk mengoptimalkan dalam menjaga atau menyerap panas yang ditimbulkan oleh mesin induk akibat pembakaran bahan bakar di dalam mesin itu sendiri. Di samping itu kualitas air pendingin sangat berpengaruh terhadap kekuatan dari material (jacket cooling) tersebut. Air pendingin yang kotor mengandung kumankuman yang mampu mengikis 
jacket cooling secara perlahan dan mempengaruhi dari kualitas ketahanan material tersebut. Maka dari itu perawatan atau pengetesan yang dilakukan pada air pendingin mesin induk atau generator sangat penting untuk mengetahui kadar air dari jacket cooling tersebut. Perawatan terhadap air pendingin dengan memberikan chemical pada air pendingin tersebut dan melakukan pengetesan-pengetesan air pendingin, antara lain:

1) Pengecekan nilai hardness mak $100 \mathrm{dH}(10 \mathrm{ppm} \mathrm{CaO})$

a) Ambil gelas ukur kecil, pastikan bersih dan masukkan sampel air pendingin $5 \mathrm{ml}$ lalu tutup gelas ukur;

b) Tambahkan 5 tetes hardness buffer melalui lubang pada tutup gelas, aduk dengan menggoyangkan gelas ukur secara halus;

c) Tambahkan 1 tetes indikator calmagite lalu larutkan sampai larutan menjadi warna merah keunguan;

d) Gunakan pipet tritasi, ambil larutan HI 3812-0 EDTA, pada tanda tera $0 \mathrm{ml}$ pada tabung pipet tritasi;

e) Masukkan ujung pipet tritasi melalui lubang pada tutup gelas ukur, lakukan tritasi secara perlahan, goyangkan gelas ukur untuk melarutkan setiap tetes tritasi. Lakukan tritasi sampai larutan menjadi ungu, setelah terjadi perubahan warna tetap aduk (putar) gelas ukur sampai larutan berwarna biru;

f) Baca tanda tera pada tabung pipet tritasi, kemudian kalikan dengan 300 untuk mendapatkan angka $\mathrm{mg} / \mathrm{L}$
CaCO3. Seperti gambar di bawah ini uraian dari langkah 1 sampai 6 pengetesan nilai hardness air pendingin jacket.

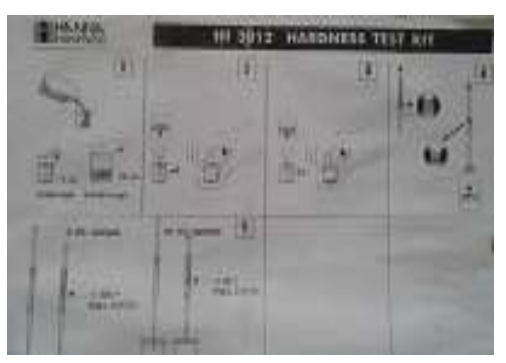

Gambar 13. Hardness test kit

2) Melakukan pengetesan nilai chloride conten

a) Ambil gelas ukur kecil, bilas atau berishkan gelas ukur kemudian tuangkan air sampai tanda tera $5 \mathrm{ml}$;

b) Teteskan 2 tetes diphenylcarbazone melalui lubang pada tutup gelas ukur, lalu goyangkan gelas ukur untuk mencampurkan larutan sampai warna larutan menjadi merah keunguan;

c) Sambil tetap mengaduk, tambahkan larutan asam nitrit sampai larutan berubah warna menjadi kuning;

d) Ambil penyemprot tritasi, masukkan jarum ke larutan mercuric nitrite $\mathrm{H} 3815$ lalu ambil larutan sampai karet pendorong pada tanda tera: $0 \mathrm{ml}$;

e) Masukkan jarum pipet tritasi melalui lubang di tutup gelas ukur, lakukan tritasi sampai larutan di gelas ukur berubah warna dari kuning menjadi ungu;

f) Baca tanda tera pada jarum penyemprotan (pipet tritasi), kalikan dengan 1000 untuk 
Suwondo $^{\mathrm{a}}$, Edy Warsopurnomo ${ }^{\mathrm{b}}$ dan Ahmad Muchlisin ${ }^{\mathrm{c}}$

mendapatkan angka $\mathrm{mg} / \mathrm{L}$ chloride.

Hasil pengetesan air pendingin terhadap nilai chloride di MT. Sei Pakning pada tanggal 03 Januari 2016 sebesar 6. Hal itu sangat mempengaruhi kualitas dari air pendingin jika semakin lama tidak ada tanggapan dan tidak diberi chemical water cooling treatment pada air pendingin di tangki ekspansi. Hasil nilai chloride dapat dilihat pada gambar 13 .

b. Menjaga kestabilan temperatur air pendingin

Kestabilan temperatur air pendingin sangat dianjurkan dalam menjaga kualitas ketahanan material jacket cooling pada mesin induk. Dengan temperatur yang stabil juga akan meningkatkan performa mesin induk dapat dibuktikan dengan mesin pada kondisi yang stabil lebih bertenaga dibandingkan ketika mesin dalam keadaan dingin atau terlalu panas (overheat). Langkah-langkah yang harus diperhatikan dalam menjaga kestabilan temperatur mesin induk antara lain:

1) Melakukan pembersihan terhadap plate fresh water central cooler secara berkala, selalu memonitor temperatur masuk air tawar ke central cooler dan temperatur keluar ke mesin induk. Pembersihan plate pada fresh water cooler sebelum masuk ke pompa pendinginan mesin induk;

2) Menjaga tekanan pompa air pendingin masuk ke mesin induk;

3) Melakukan pengecekan tekanan pada pompa pemanas awal (preheater) air pendingin, serta memonitor temperatur air masuk ke preheater dan keluar ke mesin induk;
4) Apabila pada rpm tinggi saat mesin induk beroperasi temperatur air pendingin tinggi dan penyetelan terhadap katup inlet ke mesin induk sudah full, lakukan pengalihan air keluaran dari mesin induk ke fresh water generator (FWG) dan jalankan pompa ejector pada FWG untuk bersirkulasi;

5) Pada saat olah gerak di MT. Sei Pakning salah satu cadet mesin harus standby di bawah (dekat katup penyetelan jacket cooling) dengan menggunakan halky talky (HT) yang dihubungkan ke Masinis. Untuk melakukan tindakan secara tepat dan cepat yang berkaitan dengan berubahubahnya temperatur pada saat kapal sedang olah gerak.

\section{SIMPULAN DAN SARAN}

Berdasarkan pembahasan pada bab-bab sebelumnya, tentang pengaruh keretakan jacket cooling terhadap kerja mesin induk di MT. Sei Pakning dengan metode SWOT. Sebagai bagian akhir dari penelitian ini, peneliti memberikan simpulan dan saran yang berkaitan dengan masalah yang dibahas dalam penelitian ini, yaitu:

\section{Simpulan}

Berdasarkan uraian di atas makan peneliti dapat menarik simpulan sebagai berikut:

a. Faktor yang menjadi penyebab keretakan jacket cooling di cylinder cover mesin induk selain usia dari material tersebut yaitu penyetelan temperatur air pendingin yang tidak stabil. Temperatur dan tekanan air pendingin jacket cooling main engine sesuai dengan standar di buku panduan yaitu:

Jacket cooling water (JCW) inlet : $65^{\circ} \mathrm{C}-70^{\circ} \mathrm{C}$ 
Temperatur outlet JCW

$75^{\circ} \mathrm{C}-80^{\circ} \mathrm{C}$

Tekanan JCW masuk

$3.5-4.5$ bar

Sedangkan pada saat kejadian temperatur jacket cooling naim secara drastis $810^{\circ} \mathrm{C}$. Usia dari material jacket cooling sudah melampaui batas jam kerja yaitu 16.388 jam sedangkan batas maksimum sesuai instruction manual book yaitu 8000 jam sudah diadakan penggantian.

b. Keretakan pada jacket cooling mengakibatkan kebocoran hingga air pendingin di tangki ekspansi habis dan terjadi blackout serta kerusakankerusakan pada permesinan bantu lainnya.

c. Untuk mengatasi keretakan pada jacket cooling di cylinder cover mesin induk, sebaiknya dilakukan penyetelan temperatur secara bertahap, melakukan pengetesan kadar keasaman air pendingin dan melakukan pengecekan ataupun penggantian terhadap material (jacket cooling) ketika sudah mendekati batas jam kerja yaitu 8000 jam di cylinder cover dan 16000 jam di cylinder liner agar penyebab masalah yang mengakibatkan keretakan jacket cooling di cylinder cover mesin induk teratasi. Melakukan upaya untuk menjadikan temperatur air jacket cooling main engine menjadi lebih normal dapat dilakukan dengan selalu melakukan perawatan pada central cooler, membersihkan plat-plat dari sisi air laut maupun air tawar, melakukan sirkulasi chemical (powder descaler) secara berkala, membersihkan platplat di fresh water jacket cooler (FWJC).

\section{Saran}

Berdasarkan uraian di atas maka peneliti dapat memberikan saran sebagai berikut: a. Lakukan pemeriksaan rutin terhadap kondisi/kualitas air pendingin, jaga temperatur jacket cooling tetap stabil pada saat mesin beroperasi maupun tidak beroperasi, dan melakukan penggantian jacket cooling sesuai batas jam kerja.

b. Ketika terjadi kebocoran akibat keretakan pada jacket cooling di mesin induk sebaiknya segera melakukan penutupan pada outlet valve di silinder yang bocor dan bila tidak terjangkau sebaiknya lakukan penutupan pada outlet valve di tangki ekspansi yang ke mesin induk. Hal itu dapat mencegah terjadinya kerusakan pada permesinan bantu lainnya.

c. Segera lakukan penutupan katup keluaran air pendingin di silinder yang bocor. Cek level air pendingin tangki ekspansi, pastikan airnya pada level normal dan apabila kurang segera lakukan pengisian supaya tidak kehabisan air pendingin yang bisa menyebabkan overheating di permesinan bantu lainnya. Lakukan perawatan dan perbaikan permesinan kapal khususnya sistem pendinginan (jacket cooling) secara berkala sesuai dengan plain maintenance system (PMS) yang ada di kapal.

\section{DAFTAR PUSTAKA}

Fatimah, Dwi NF. 2009. Analisis SWOT Teknik Analisi SWOT. Jakarta: Buku Pintar Publisher

Handoyo, Jusak Johan. 2014. Mesin Penggerak Utama Motor Diesel. Yogyakarta : Deepublish

Instruction manual book. 2011. Hyundai Man $B \& W \quad 6 S 42 M C 7$ Diesel Engine Operation, Maintenance and Data. China 
Suwondo $^{\mathrm{a}}$, Edy Warsopurnomo $^{\mathrm{b}}$ dan Ahmad Muchlisin ${ }^{\mathrm{c}}$

Sugiono. 2009. Metode Penelitian Kuantitatif dan Kualitatif dan $R \& D$. Bandung: Alfabeta.

Suharsimi, Arikunto. 2002. Prosedur Penelitian. Jakarta: Rineka Cipta

(http://www.pelajaran.co.id/2017/29/penger tian-analisis-menurut-paraahli.html). Diakses pada tanggal 21 September 2017

(http://www.pelajaran.co.id/2017/29/penger tian-analisis-menurut-paraahli.html). Diakses pada tanggal 21 September 2017

https://www.tapatalk.com/groups/dunialistr ikfr/ask-definisi-blackout-t656.html. Diakses pada tanggal 26 September 2017

http://enginekomponenardiansyahab.blogsp ot.co.id/2011/10/engine-

komponen.html. Diakses pada tanggal 27 September 2017

http://migas-

indonesia.com/2005/12/15/mengapa -pengelasan-castiron- sering-terjadiretak/). Diakses pada tanggal 4 Oktober 2017 